\title{
A new mutation of the ATP-binding cassette, sub-family $C$, member 2 (ABCC2) gene in a Japanese patient with Dubin-Johnson syndrome
}

\author{
Genshu Tate*, Min Li, Takao Suzuki and Toshiyuki Mitsuya \\ Department of Surgical Pathology, Showa University Fujigaoka Hospital, \\ Fujigaoka 1-30, Aoba-ku, Yokohama 227-8501, Japan.
}

(Received 15 January 2002, accepted 1 April 2002)

\begin{abstract}
Dubin-Johnson syndrome (DJS) is an inherited disorder characterized by conjugated hyperbilirubinemia and is caused by mutations of the canalicular multispecific organic anion transporter (cMOAT)/ multidrug resistance protein 2 (MRP2)/ ATP-binding cassette, sub-family $\mathrm{C}$, member 2 (ABCC2) gene. The ABCC2 protein is located in the apical membrane of hepatocytes, and known mutations of this gene cause impaired maturation and trafficking of the mutated protein from the endoplasmic reticulum (ER) to the Golgi complex. We have characterized the ABCC2 gene in a Japanese DJS patient by polymerase chain reaction and DNA sequencing, resulting in the identification of two mutations. One mutation, $1815+2(\mathrm{~T}>\mathrm{A})$ in the splice donor site of intron 13, has already been reported. However, we have identified a novel nonsense mutation consisting of a $(\mathrm{C}>\mathrm{T})$ transition at nucleotide 3928 in exon 28.
\end{abstract}

\section{INTRODUCTION}

Dubin-Johnson syndrome (DJS; MIM 237500) is an autosomal recessive disorder which is characterized by chronic conjugated hyperbilirubinemia, impaired secretion of anionic conjugates from hepatocytes into the bile and deposition of brown pigments in the liver (Dubin and Johnson, 1954). The deficient hepatobiliary transport of anionic conjugates in DJS patients is caused by the absence of a functional multidrug-resistance protein 2 (MRP2)/ ATP-binding cassette, sub-family C, member 2 (ABCC2) (Keitel et al., 2000). ABCC2 protein is an integral membrane glycoprotein that is expressed in the apical (canalicular) membrane of hepatocytes and mediates the primary active export from cells of conjugates of lipophilic compounds with glucuronate or glutathione in a manner dependent on adenosine triphosphate (ATP) (Ishikawa et al., 1990; Taniguchi et al., 1996; Jedlitschky et al., 1997; Cui et al., 1999).

$\mathrm{ABCC} 2$ is a member of the ATP-binding cassette $(\mathrm{ABC})$ transporter superfamily (Higgins, 1992). Mutations in members of the ABC transporter superfamily cause several diseases, including cystic fibrosis (Riordan, 1989), Stargardt macular dystrophy (Allikmets, 1997), familial persistent hyperinsulinemic hypoglycemia of infancy (Thomas, 1995), X-linked adrenoleukodystrophy (Mosser, 1993) and multidrug resistance (Roninson, 1986). The Walker A, B motif and the active transport family signa-

Edited by Tatsuro Ikeuchi

* Corresponding author. E-mail: six10352@super.win.ne.jp ture, also called the $\mathrm{C}$ motif, in the $\mathrm{ABC}$ regions are highly conserved among members of the $\mathrm{ABC}$ transporter superfamily, and are important for the ATP binding. There are two $\mathrm{ABC}$ sites in the $\mathrm{ABCC} 2$ protein, and mutations of the $\mathrm{ABCC} 2$ gene in DJS have been identified within and/or around these ABC sites in almost all the cases of DJS examined thus far. The impaired transport of glucuronides and other anionic conjugates from hepatocytes into the bile is caused by the absence from the canalicular membrane of a 190-kilodalton glycoprotein originally termed canalicular multidrug- resistance protein (Taniguchi et al., 1996).

The ABCC2 gene, also known as canalicular multispecific organic anion transporter (cMOAT), was initially cloned from the rat liver (Buchler et al., 1996; Paulusma et al., 1996) and subsequently cloned from the human liver, and the first mutations of the $\mathrm{ABCC} 2$ gene in patients with DJS were detected in 1997 (Paulusma et al., 1997). The human ABCC2 gene, which has been localized to chromosome 10q24 (van Kuijck et al., 1997), spans about 45 kilobases and contains 32 exons ranging in size from 56 to 255 base pairs (Tsujii et al., 1999). So far, nine kinds of mutations of the ABCC2 gene have been reported (Kajihara et al., 1998; Tsujii et al., 1999; Toh et al., 1999; Mor-Cohen et al., 2001). In this study, we report a new mutation of the ABCC2 gene in a Japanese DJS patient. 


\section{MATERIALS AND METHODS}

Patient and tissue samples The patient was a 17year-old Japanese female who had suffered from intermittent jaundice which started when she was 7 years old. Common bile duct stones were detected and an operation was carried out when she was 17 years old. The total bilirubin level was elevated (approximately 2 to 3 $\mathrm{mg} / \mathrm{dl}$ ). When cholecystectomy was carried out, black liver was noted. Histopathologic examination of the liver biopsy specimens revealed abundant, coarse granules containing dark, golden-brown pigments in the cytoplasm of the liver cells. The final diagnosis of DJS was made based on the clinical findings, laboratory data and histopathologic findings. Informed consent for genetic analysis was obtained from the patient and her mother. Her parents, divorced at present, are not consanguineous, and have never suffered from jaundice.

Amplification of genomic DNA Genomic DNA was prepared from peripheral blood leukocytes by standard methods using phenol/chloroform extraction and ethanol precipitation. The exons and the intron/exon boundaries in the $\mathrm{ABCC} 2$ gene were analyzed by polymerase-chainreaction (PCR) and direct sequencing of the PCR products (Umehara et al., 2000). The primers used for the amplification of the genomic DNA were as follows:

DJS/ex 13\#1, 5'-GGA GGC TGG ATG ATC CTT AAG-3', DJS/ex 13\#2, 5'-TAG CAG TGA GAA TGC CGA CC-3',
DJS/ex 28\#1, 5'-TGG GTG GAC TGT TCG GCT GAG TTG-3', DJS/ex 28\#2, 5'-AAT GAT GAA GGC TTA GGG CC-3'. Amplified DNA fragments were recovered from a low melting agarose gel and used for the sequencing analysis.

Reverse Transcriptase-PCR (RT-PCR) Total RNA from peripheral blood leukocytes was isolated using of TriPure isolation reagent (Bohringer/Roche). Firststrand synthesis of cDNA from total RNA was performed using random hexanucleotide primers and Moloney murine leukemia-virus reverse transcriptase (Wako). The

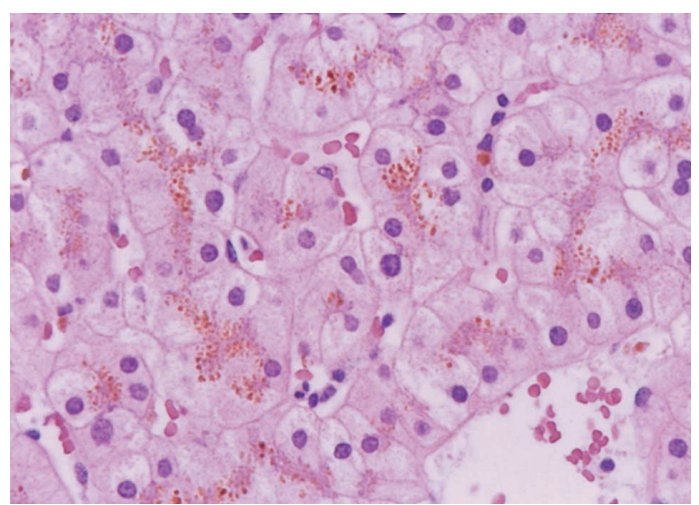

Fig. 1. Histopathology of the liver in the DJS patient. Histopathologic examination of the liver biopsy specimen from the DJS patient showed the brown pigment accumulation on the apical side of hepatocytes characteristic of DJS (HematoxylinEosin stain, X400).
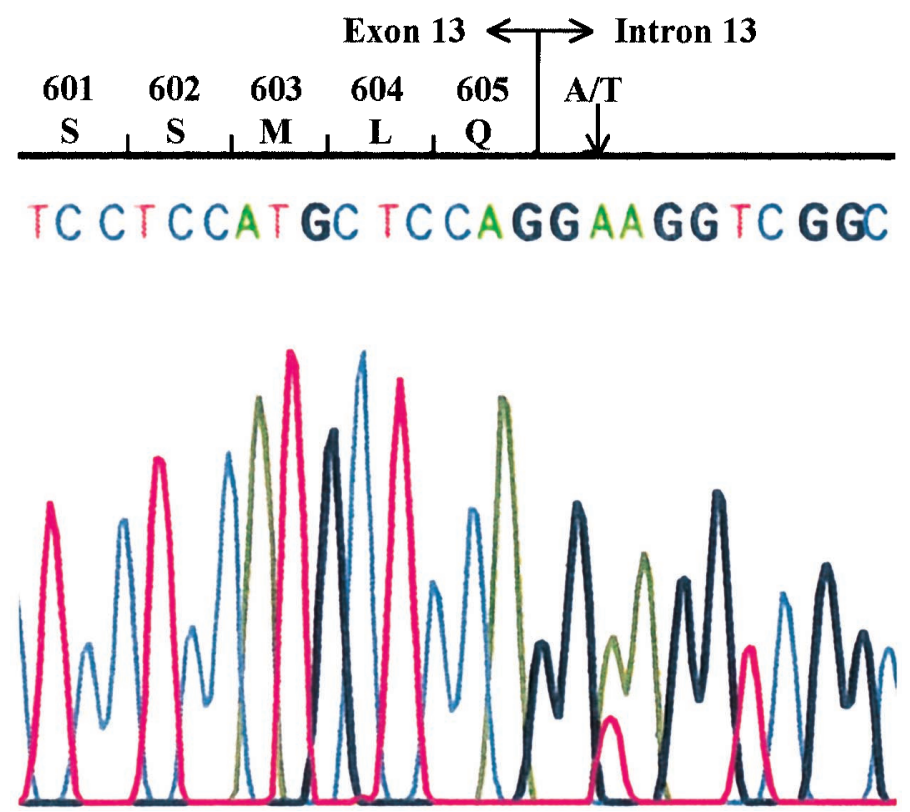

Fig. 2. A splicing mutation in intron 13 of the ABCC2 gene in the DJS patient. Genomic DNA sequence analysis at the splicing donor site of intron 13 revealed a heterozygous $\mathrm{T}$ to A substitution $(1815+2$, IVS13+2 T $>\mathrm{A})$. An arrow indicates the overlapping nucleotide sequences. The nucleotide $\mathrm{T}$ occurs in the wild-type sequence and the nucleotide $\mathrm{A}$ in the mutated sequence. Amino acid numbers are shown. 
single-stranded cDNA was amplified by nested PCR. For $\mathrm{PCR}, 30$ cycles of denaturation $\left(98^{\circ} \mathrm{C}\right.$ for $\left.1 \mathrm{~min}\right)$, annealing $\left(65^{\circ} \mathrm{C}\right.$ for $\left.2 \mathrm{~min}\right)$ and extension $\left(72^{\circ} \mathrm{C}\right.$ for $\left.3 \mathrm{~min}\right)$ were performed (Quick Thermo Personal. Nippon Genetics Co, Ltd). The primers used for the nested RT-PCR were as follows:

DJS/ex 12/\#3, 5'-CCT TTA GTC AAC TAC AGT GTG TAG-3',

DJS/ex 12/\#4, 5'ATA TTC GTC TTC CAG TTA ACT C-3',

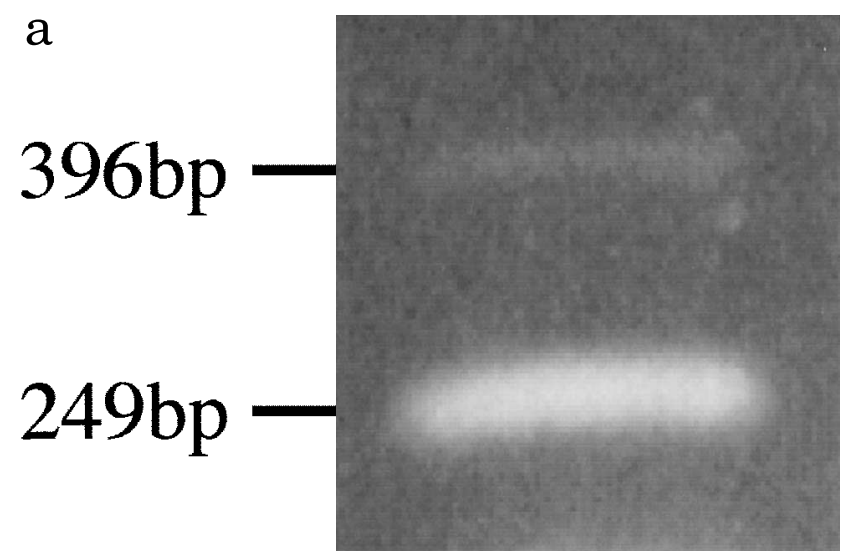

b

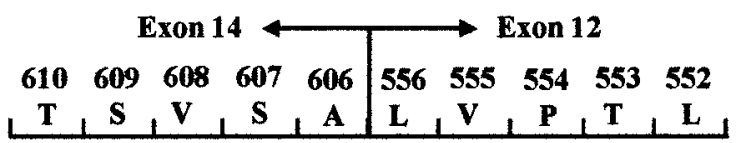

T GT GGAA ACAC T GGC CA GGAC T GGA GT TAA.

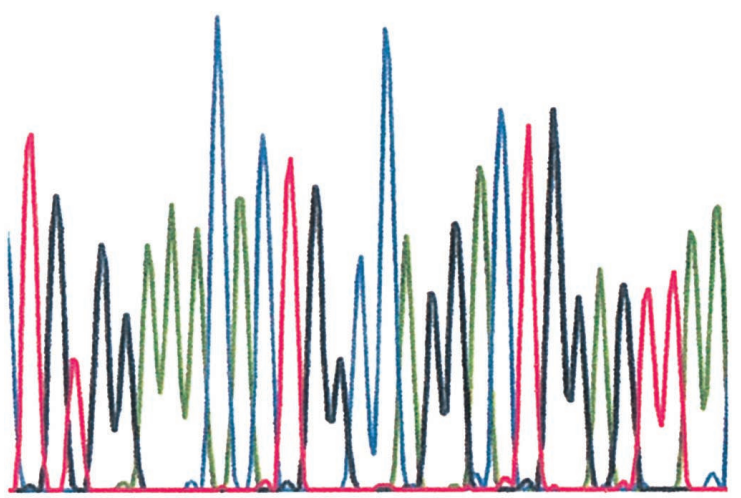

Fig. 3. (a) Agarose gel electrophoresis of RT-PCR fragments of RNAs from the DBJ patient. Primers DJS/ex 12/\#3 and DJS/ex 18/\#3 were used for amplification. Then nested PCR was carried out using primers DJS/ex 12/\#4 and DJS/ex 16/\#4. The size of the amplified fragments is shown. One fragment, $396 \mathrm{bp}$ in size, is the same size as in the wild-type and another smaller fragment, $249 \mathrm{bp}$, represents a mutated message which lacks exon 13. (b) Deletion of exon 13 of the ABCC2 gene in the DJS patient. Sequence analysis of the smaller fragment, $249 \mathrm{bp}$, obtained from the nested RT-PCR showed that exon 13 was skipped and exon 12 was joined in-frame with exon 14 . The reverse-complementary nucleotide sequence is shown.
DJS/ex 18/\#3, 5'-GGC CAG GCT GAT CCG CTG CTT CTG-3,

DJS/ex 16/\#4, 5'-GGA TTT CCC AGA GCC GAC AG-3'.

Sequencing and identification of mutations We sequenced the PCR or RT-PCR products directly by using a DNA sequencing system (model 377; Applied Biosystems). The direct sequencing was performed in both directions and the mutation analysis was repeated independently.

\section{RESULTS AND DISCUSSION}

Histopathologic examination of the liver biopsy sample from the patient with DJS revealed brown pigment accumulation in hepatocytes, which is characteristic of DJS (Fig. 1).

We successfully screened this patient with DJS for ABCC2 mutations. As shown in Fig. 2, mutational analysis of the ABCC2 gene using primers DJS ex13\#1 and \#2 revealed a heterozygous single nucleotide transversion at nucleotide $1815+2(\mathrm{~T}>\mathrm{A})$ in the splice donor site of intron 13.

Fig. 3a shows agarose gel electrophoresis of the nested RT-PCR product of the DJS patient. Not only a fragment 396 base pairs (bp) in size, but also a smaller fragment, 249 bp in size, was observed. In contrast, the nested RT-PCR product obtained from normal individuals showed a single fragment, $396 \mathrm{bp}$ in size (data not shown). We isolated the smaller fragment and analyzed its nucleotide sequence. RT-PCR analysis followed by direct sequencing showed that this mutation caused the deletion of exon 13 in the ABCC2 mRNA (Fig. 3b).
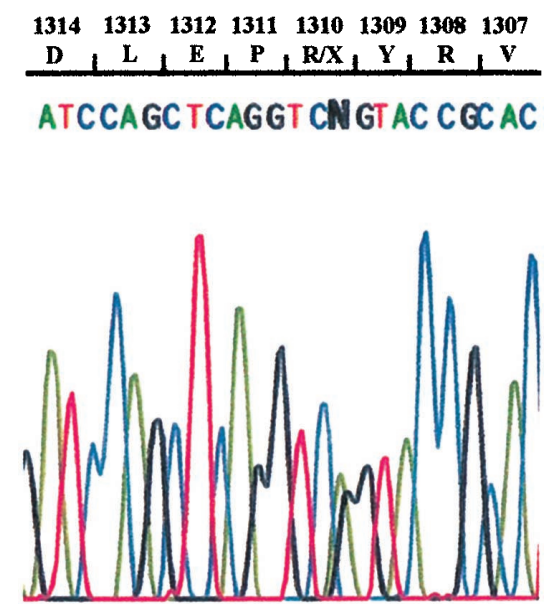

Fig. 4. A nonsense mutation in exon 28 of the ABCC2 gene in the DJS patient. Genomic DNA sequence analysis of exon 28 revealed a heterozygous transition at nucleotide 3928 in exon 28 , which is shown by $\mathrm{N}$, resulting in a premature termination codon (3928 C>T). $\mathrm{N}$ indicates the overlapping nucleotides, $\mathrm{A}$ and G. The reverse-complementary nucleotide sequence is shown. 
Table 1. Summary of ABCC2 mutations in DJS

\begin{tabular}{|c|c|c|c|c|c|c|}
\hline Mutation & Splice mutation & Splice site & Exon & IVS & Amino acid & Source \\
\hline $1815+2(\mathrm{~T}>\mathrm{A})$ & Yes & Donor & & 13 & exon 13 skipped & Toh et al. (1999), present study \\
\hline $1967+2(\mathrm{~T}>\mathrm{C})$ & Yes & Donor & & 15 & exon 15 skipped & Kajihara et al. (1998) \\
\hline $2302(\mathrm{C}>\mathrm{T})^{\mathrm{a}}$ & No & $\ldots$. & 18 & & R768W & Wada et al. (1998) \\
\hline $2439+2, \mathrm{IVS}^{\mathrm{b}} 18+2(\mathrm{~T}>\mathrm{C})$ & Yes & Donor & & 18 & exon 18 skipped & Toh et al. (1999) \\
\hline $3196(\mathrm{C}>\mathrm{T})$ & No & $\ldots$. & 23 & & R1066X & Paulusma et al. (1997) \\
\hline $3517(\mathrm{~A}>\mathrm{T})$ & No & $\ldots$. & 25 & & $\mathrm{I} 1173 \mathrm{~F}$ & Mor-Cohen et al. (2001) \\
\hline $3449(\mathrm{G}>\mathrm{A})$ & No & $\ldots$. & 25 & & $\mathrm{R} 1150 \mathrm{H}$ & Mor-Cohen et al. (2001) \\
\hline $3928(\mathrm{C}>\mathrm{T})$ & No & $\ldots$. & 28 & & $\mathrm{R} 1310 \mathrm{X}$ & present study \\
\hline $4145(\mathrm{~A}>\mathrm{G})$ & No & $\ldots$. & 29 & & Q1382R & Toh et al. (1999) \\
\hline 4175_4180delGGATGA & No & $\ldots$. & 30 & & R1392M1393del & Tsujii et al (1999) \\
\hline
\end{tabular}

${ }^{a}$ Nucleotide position 1 is the A in the ATG translation initiation codon in the ABCC2 cDNA sequence.

${ }^{\mathrm{b}} \mathrm{IVS}=$ intervening sequence

In addition, we found a heterozygous single nucleotide transition from $\mathrm{C}$ to $\mathrm{T}$ at nucleotide 3928 , which resulted in the introduction of a premature termination codon in exon 28 (Fig. 4). Direct sequencing analysis of genomic DNA obtained from her mother revealed the same mutation at nucleotide $1815+2(\mathrm{~T}>\mathrm{A})$ as shown in the patient, but the sequence of exon 28 was the wild type (data not shown). Although her father's genetic analysis was unavailable, her mother's genetic analysis indicated that both alleles of the ABCC2 gene were probably mutated in this patient. Namely, one ABCC2 gene inherited from her mother caused an inappropriate exon 13 skipping, and another ABCC2 gene inherited from her father showed a premature termination codon in exon 28 . As shown in Fig. 3a, the signal of the 396-bp fragment was very faint compared with that of the smaller fragment, $249 \mathrm{bp}$ in size. This finding indicates nonsense-mediated mRNA decay (NMD), because the 396-bp fragment contained a nonsense mutation in exon 28 (Peltz et al., 1994). The novel mutation in exon 28 eliminates a restriction enzyme site, Kpn I; therefore digestion with $K p n \mathrm{I}$ is very useful for screening many individuals.

There are two $\mathrm{ABC}$ sites in the $\mathrm{ABCC} 2$ protein, and mutations of the $\mathrm{ABCC} 2$ gene have been identified within and around these $\mathrm{ABC}$ sites in almost all cases of DJS. As shown in Table 1, nine kinds of mutations in the ABCC2 gene have already been reported in DJS patients. Three of these are splice mutations at donor sites, and result in exon skipping (Kajihara et al., 1998; Toh et al., 1999). Four of the mutations are missense mutations (Wada et al., 1998; Toh et al., 1999; Mor-Cohen et al., 2001) and one mutation is a nonsense mutation (Paulusma et al., 1997). One of the mutations is a 6-base deletion in the exon 30 (Tujii et al., 1999). A nonsense mutation detected in the present study, which resulted in the absence of the second $\mathrm{ABC}$ site, is the first one found in a DJS patient, although the additional mutation of the splice donor site of intervening sequence (IVS) 13 was previously reported in a Japanese DJS patient (Toh et al., 1999).

Recently, polymorphism of the ABCC2 gene in healthy Japanese subjects was reported (Ito et al., 2001). Two mutations of the $\mathrm{ABCC} 2$ gene found in the present study were not found in that study. It is important to analyze mutations of the ABCC2 gene in DJS, because it is estimated that there are approximately 200,000 healthy carriers of DJS in Japan (Takino et al., 1977). Analysis of the ABCC2 gene in DJS will provide important information not only for genetic counseling but also for research to examine whether there are correlations between the site of mutation of the ABCC2 gene and the pattern of alteration of the clinical laboratory findings regarding liver function in JDS.

We thank the patient and her mother for making this study possible, and Dr. Kazutaka Kirihara for the preparation of the blood samples. This work was supported in part by the HighTechnology Center Project from the Ministry of Education, Science, Sports and Culture of Japan (GT).

\section{REFERENCES}

Allikmets, R., Singh, N., Sun, H., Shroyer, N. F., Hutchinson, A., Chidambaram, A., Gerrard, B., Baird, L., Stauffer, D., Peiffer, A., Rattner, A., Smallwood, P., Li, Y., Anderson, K. L., Lewis, R.A., Nathans, J., Leppert, M., Dean, M. and Lupski, J. R. (1997) A photoreceptor cell-specific ATP-binding transporter gene (ABCR) is mutated in recessive Stargardt macular dystrophy. Nature Genet. 15, 236-246.

Buchler, M., Konig, J., Brom, M., Kartenbeck, J., Spring, H., Horie, T. and Keppler, D. (1996) cDNA cloning of the hepatocyte canalicular isoform of the multidrug resistance protein, cMRP, reveals a novel conjugate export pump deficient in hyperbilirubinemic mutant rats. J. Biol. Chem. 271, 15091-15098.

Cui, Y., Konig, J., Buchholz, U., Spring, H., Leier, I. and Keppler, D. (1999) Drug resistance and ATP-dependent conjugate transport mediated by the apical multidrug resistance 
protein, MRP2, permanently expressed in human and canine cells. Mol. Pharmacol. 55, 929-937.

Dubin, I. N. and Johnson, F. B. (1954) Chronic idiopathic jaundice with unidentified pigment in liver cells: new clinicopathologic entity with report of 12 cases. Medicine 33, 155-179.

Higgins, C. F. (1992) ABC transporters: from microorganisms to man. Annu. Rev. Cell Biol. 8, 67-113.

Ishikawa, T., Muller, M., Klunemann, C., Schaub, T. and Keppler, D. (1990) ATP-dependent primary active transport of cysteinyl leukotrienes across liver canalicular membrane. Role of the ATP-dependent transport system for glutathione S-conjugates. J. Biol. Chem. 265, 19279-19286.

Ito, S., Ieiri, I., Tanabe, M., Suzuki, A., Higuchi, S. and Otsubo, K. (2001) Polymorphism of the ABC transporter genes, MDR1, MRP1 and MRP2/cMOAT, in healthy Japanese subjects. Pharmacogenetics 11, 175-184.

Jedlitschky, G., Leier, I., Buchholz, U., Hummel-Eisenbeiss, J., Burchell, B. and Keppler, D. (1997) ATP-dependent transport of bilirubin glucuronides by the multidrug resistance protein MRP1 and its hepatocyte canalicular isoform MRP2. Biochem. J. 327, 305-310.

Kajihara, S., Hisatomi, A., Mizuta, T., Hara, T., Ozaki, I., Wada, I. and Yamamoto, K. (1998) A splice mutation in the human canalicular multispecific organic anion transporter gene causes Dubin-Johnson syndrome. Biochem. Biophys. Res. Commun. 253, 454-457.

Keitel, V., Kartenbeck, J., Nies, A.T., Spring, H., Brom, M. and Keppler, D. (2000) Impaired protein maturation of the conjugate export pump multidrug resistance protein 2 as a consequence of a deletion mutation in Dubin-Johnson syndrome. Hepatology 32, 1317-1328.

Mor-Cohen, R., Zivelin, A., Rosenberg, N., Shani, M., Muallem, S. and Seligsohn, U. (2001) Identification and functional analysis of two novel mutations in the multidrug resistance protein 2 gene in Israeli patients with Dubin-Johnson syndrome. J. Biol. Chem. 5, 36923-36930.

Mosser, J., Douar, A. M., Sarde, C. O., Kioschis, P., Feil, R., Moser, H., Poustka, A. M., Mandel, J. L. and Aubourg, P. (1993) Putative X-linked adrenoleukodystrophy gene shares unexpected homology with ABC transporters. Nature 361, 726-730.

Paulusma, C. C., Bosma, P. J., Zaman, G. J., Bakker, C. T., Otter, M., Scheffer, G. L., Scheper, R. J., Borst, P. and Oude Elferink, R. P. (1996) Congenital jaundice in rats with a mutation in a multidrug resistance-associated protein gene. Science 271, 1126-1128.

Paulusma, C. C., Kool, M., Bosma, P. J., Scheffer, G. L., ter Borg, F., Scheper, R. J., Tytgat, G. N., Borst, P., Baas, F. and Oude Elferink, R.P. (1997) A mutation in the human canalicular multispecific organic anion transporter gene causes the Dubin-Johnson syndrome. Hepatology 25, 15391542 .

Peltz, S. W., He, F., Welch E. and Jacobson, A. (1994) Nonsense- mediated mRNA decay in yeast. Prog. Nucleic Acid Res. Mol. Biol. 47, 271-298.

Riordan, J. R., Rommens, J. M., Kerem, B., Alon, N., Rozmahel, R., Grzelczak, Z., Zielenski, J., Lok, S., Plavsic, N. and Chou, J.L.(1989) Identification of cystic fibrosis gene: cloning and characterization of complementary DNA. Science 245, 1066-1073.

Roninson, I. B., Chin, J. E., Choi, K. G., Gros, P., Housman, D. E., Fojo, A., Shen, D. W., Gottesman, M. M. and Pastan, I. (1986) Isolation of human mdr DNA sequences amplified in multidrug-resistant KB carcinoma cells. Proc. Natl. Acad. Sci. USA 83, 4538-4542.

Takino, T., Takahashi, T. and Okuno, T. (1977) Clinical study of the constitutional hyperbilirubinemia in Japan. A nationwide survey between 1970 and 1974. Jpn. J. Gastroenterol. 74, 1518-1528.

Taniguchi, K., Wada, M., Kohno, K., Nakamura, T., Kawabe, T., Kawakami, M., Kagotani, K., Okumura, K., Akiyama, S. and Kuwano, M. (1996) A human canalicular multispecific organic anion-transporter (cMOAT) gene is overexpressed in cisplatin-resistant human cancer cell lines with decreased drug accumulation. Cancer Res. 56, 4124-4129.

Thomas, P. M., Cote, G. J., Wohllk, N., Haddad, B., Mathew, P. M., Rabl, W., Aguilar-Bryan, L., Gagel, R. F. and Bryan, J. (1995) Mutations in the sulfonylurea receptor gene in familial persistent hyperinsulinemic hypoglycemia of infancy. Science 268, 426-429.

Toh, S., Wada, M., Uchiumi, T., Inokuchi, A., Makino, Y., Horie, Y., Adachi, Y., Sakisaka, S. and Kuwano, M. (1999) Genomic structure of the canalicular multispecific organic aniontransporter gene (MRP2/cMOAT) and mutations in the ATP-binding cassette region in Dubin-Johnson syndrome. Am. J. Hum. Genet. 64, 739-746.

Tsujii, H., Konig, J., Rost, D., Stockel, B., Leuschner, U. and Keppler D (1999) Exon-intron organization of the human multidrug resistance protein 2 (MRP2) gene mutated in Dubin-Johnson syndrome. Gastroenterology 117, 653-660.

Umehara, F., Tate, G., Yamaguchi, N., Douchi, T., Mitsuya, T. and Osame, M. (2000) A novel mutation of Desert Hedgehog in a patient with $46, \mathrm{XY}$ partial gonadal dysgenesis accompanied by minifascicular neuropathy. Am. J. Hum. Genet. 67, 1302-1305.

Van Kuijck, M. A., Kool, M., Merkx, G. F. M., Geurts van Kessel, A., Bindels, R. J. M., Deen, P. M. T. and van Os, C. H. (1997) Assignment of the canalicular multispecific organic anion transporter gene (CMOAT) to human chromosome 10q24 and mouse chromosome 19D2 by fluorescent in situ hybridization. Cytogenet. Cell Genet. 77, 285-287.

Wada, M., Toh, S., Taniguchi, K., Nakamura, T., Uchiumi, T., Kohno, K., Yoshida, I., Kimura, A., Sakisaka, S., Adachi, Y. and Kuwano, M. (1998) Mutations in the canalicular multispecific organic anion transporter (cMOAT) gene, a novel ABC transporter, in patients with hyperbilirubinemia/ Dubin-Johnson syndrome. Hum. Mol. Genet. 7, 203-207. 